\title{
ГИДРОТРАНСПОРТ СГУЩЕННЫХ ХВОСТОВ ОБОГАЩЕНИЯ ЖЕЛЕЗНОЙ РУДЫ НА КАЧКАНАРСКОМ ГОКЕ ПО РЕЗУЛЬТАТАМ ОПЫТНО-ПРОМЫШЛЕННЫХ ИСПЫТАНИЙ СИСТЕМЫ ГИДРОТРАНСПОРТА
}

\author{
В.И.АЛЕКСАНДРОВ, М.А.ВАСИЛЬЕВА \\ Санкт-Петербургский горный университет, Санкт-Петербург, Россия
}

\begin{abstract}
В качестве объекта исследования выступает система гидротранспорта хвостов обогащения железной руды на АО «ЕВРАЗ Качканарский ГОК». Целью работы являлось определение параметров гидравлического транспорта хвостов обогащения железной руды при массовых концентрациях твердой фазы от 30 до $70 \%$ и разработка рекомендаций для промышленной эксплуатации систем гидротранспорта высоконцентрированных пульп ЦХХ Качканарского ГОКа. Проведены лабораторные исследования параметров гидротранспорта сгущенных хвостовых пульп с разработкой методики расчета; опытно-промышленные испытания гидротранспортной системы в условиях ЦХХ Качканарского ГОКа. Установлено, что при использовании полиуретановых покрытий внутренней поверхности пульповодов значительно (в 1,75 раза) снижаются удельные потери напора на гидротранспорт сгущенных смесей. Это позволяет значительно увеличить дальность транспортирования для укладки хвостов обогащения в дальние участки хвостохранилища. Внедрение результатов исследований - в проекте реконструкции и развития хвостохранилища ЦХХ Качканарского ГОКа на период 2018-2020 гг. Предлагается использовать результаты работы в проекте реконструкции системы гидротранспорта в ЦХХ Качканарского ГОКа путем перехода на гидротранспорт гидросмесей, сгущенных до массовых концентраций 35-40 \% в пульповодах с внутренним полиуретановым покрытием, что обеспечит энергосбережение в технологическом процессе гидротранспорта.

Ключевые слова: гидротранспорт; сгущенные гидросмеси; хвосты обогащения; потери напора; полиуретановые покрытия; лабораторные и опытно-промышленные испытания

Как цитировать эту статью: Александров В.И. Гидротранспорт сгущенных хвостов обогащения железной руды на Качканарском ГОКе по результатам опытно-промышленных испытаний системы гидротранспорта / В.И.Александров, М.А.Васильева // Записки Горного института. 2018. Т. 233. С. 471-479. DOI: 10.31897/PMI.2018.5.471
\end{abstract}

Введение. Одним из важных направлений интенсификации горно-рудного производства, повышения его эффективности и конкурентоспособности в условиях современных рыночных отношений является создание мощной транспортной базы, способной значительно повысить производительность транспортных систем при одновременном снижении себестоимости транспортных перевозок минерального сырья и продуктов его переработки. Развитие такой базы связано с внедрением непрерывных видов транспорта, среди которых наибольшее распространение в горной отрасли получил гидравлический трубопроводный транспорт.

В настоящее время в горно-рудном промышленном комплексе функционирует около 400 напорных гидротранспортных систем, суммарная длина трубопроводной магистрали которых превышает 1300 км. Этими системами ежегодно перемещается более 1,5 млрд т различных твердых сыпучих материалов, в основном хвостов обогащения минерального сырья и концентратов [13].

АО «ЕВРАЗ КГОК» входит в пятерку крупнейших в России горно-рудных предприятий. Производственная мощность комбината составляет более 55 млн т железной руды в год. Основным потребителем продукции АО «ЕВРАЗ КГОК» является АО «ЕВРАЗ НТМК». В настоящее время Качканарский горно-обогатительный комбинат добывает руду из трех карьеров с дальнейшей ее переработкой в цехах дробления, обогащения, агломерации и окускования [3].

Анализ работы гидротранспортных систем на горных предприятиях показывает, что эффективность использования этого вида транспорта не соответствует его техническим возможностям, высока трудоемкость работ при эксплуатации оборудования, высок гидроабразивный износ трубопроводов, высоки металлоемкость и энергоемкость гидротранспортных систем.

Удельная энергоемкость гидравлического транспорта зависит от удельных потерь напора и концентрации твердой фазы гидросмеси [1]:

$$
E=\frac{N}{q_{\mathrm{TB}} L}=\frac{\rho_{\text {см }} g I_{\mathrm{cm}}}{3,6 \rho_{\mathrm{тв}} c_{\text {об }}},
$$




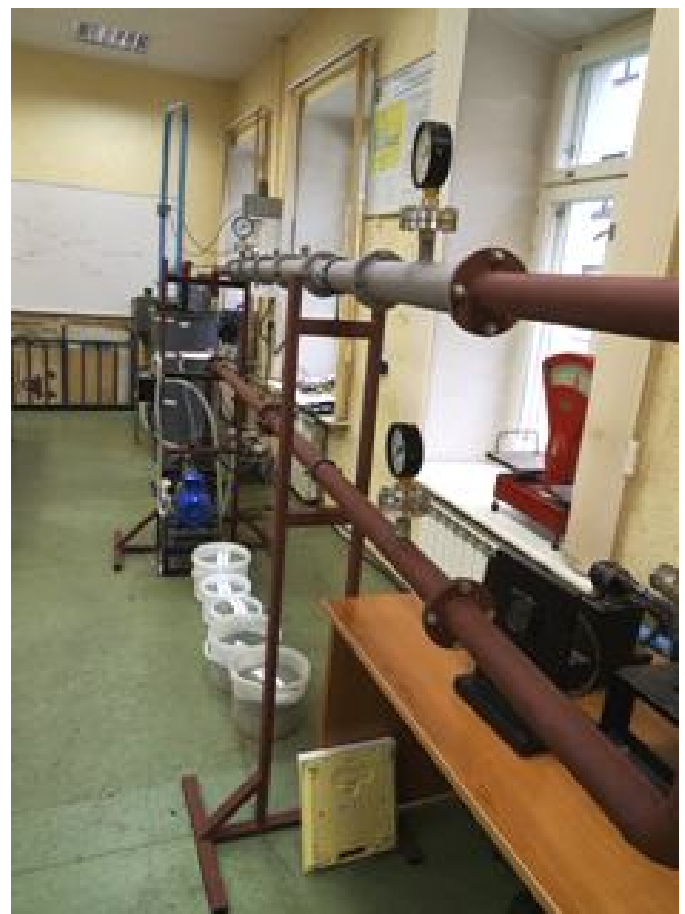

Рис.1. Лабораторная гидротранспортная установка

где $E$ - удельная энергоемкость процесса, кВт·ч/(т•км); $N$ - мощность насосов, кВт; $q_{\text {тв }}-$ производительность системы по твердому материалу, кг/ч; $L$ - длина трубопровода (расстояние транспортирования), км; $\rho_{\mathrm{cm}}-$ плотность гидросмеси, кг $/ \mathrm{M}^{3} ; \rho_{\text {тв }}-$ плотность твердых хвостов, кг $/ \mathrm{M}^{3} ; g-$ ускорение силы тяжести, м/ $\mathrm{c}^{2} ; I_{\mathrm{cm}}-$ удельные потери напора, м вод. ст./м; $c_{\text {об }}-$ объемная концентрация твердых частиц в гидросмеси.

Из формулы видно, что энергоемкость процесса транспортирования в основном зависит от удельных

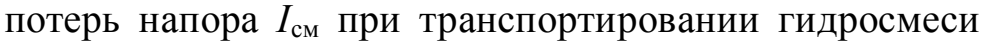
(хвостовой пульпы) по трубопроводу и от величины концентрации $c_{\text {об }}$ твердой фазы в транспортируемом потоке гидросмеси. Снижение потерь напора и увеличение концентрации приводят к уменьшению работы на перекачку заданного объема твердого материала хвостов обогащения.

Исследования. Лабораторные исследования гидротранспорта хвостовой пульпы Качканарского ГОКа проводились в лаборатории кафедры горных транспортных машин Санкт-Петербургского горного университета. Экспериментальная гидротранспортная установка показана на рис.1. Жидкость (чистая вода или гидросмесь) из зумпфа вместимостью $0,5 \mathrm{~m}^{3}$ перекачивалась по трубопроводам с помощью центробежного насоса П12.5/12.5СП производительностью $12,5 \mathrm{~m}^{3} /$ ч. В качестве твердого материала были взяты хвосты обогащения железной руды ЦХХ Качканарского ГОКа, предоставленные комбинатом для выполнения лабораторных экспериментов. Хвосты характеризуются определенным химическим составом, а их механические характеристики определяются принятой технологией обогащения.

Технология обогащения титаномагнетитовых руд на Качканарском ГОКе включает четырехстадийное дробление, сухую магнитную сепарацию, двухстадийное измельчение, мокрую магнитную сепарацию в третьей стадии, обезвоживание концентрата. Химический состав хвостов обогащения по данным ИМГРЭ [4], \%: окись кремния $\left(\mathrm{SiO}_{2}\right)-45,02$; диоксид титана $\left(\mathrm{TiO}_{2}\right)-0,67$; оксид алюминия $\left(\mathrm{Al}_{2} \mathrm{O}_{3}\right)-8,6$; оксид железа $\left(\mathrm{Fe}_{2} \mathrm{O}_{3}\right)-17,7$; оксид двухвалентного железа $(\mathrm{FeO})$ 3,95 ; оксид марганца $(\mathrm{MnO})-0,14$; окись кальция $(\mathrm{CaO})-20,8$; оксид натрия $\left(\mathrm{Na}_{2} \mathrm{O}\right)-0,90$; прочие $-2,24$.

Гранулометрический состав твердых частиц хвостов обогащения по классам крупности приведен ниже:

$\begin{array}{lcccccc}\text { Класс крупности, мм } & +1,6 & -1,60+0,56 & -0,56+0,28 & -0,28+0,14 & -0,14+0,071 & -0,071 \\ \text { Содержание, } \% & 3,6 & 25,3 & 23,0 & 20,7 & 14,8 & 12,6\end{array}$

Хвосты обогащения, представленные лабораторией Качканарского ГОКа, взяты с пляжа хвостохранилища. В объеме хвостов присутствует значительная доля крупнозернистых твердых частиц с включениями металлических фракций от шаров, применяемых в шаровых мельницах на стадии измельчения.

По данным гранулометрического состава видно, что твердый материал представлен, в основном, классами крупности частиц $-0,14$ мм $-27,4 \%$, класса $-0,071-12,6 \%$. Средневзвешенный диаметр частиц равен

$$
d_{\mathrm{cp}}=\frac{\sum_{i=1}^{n=5} P_{i} d_{i}}{100}=\frac{1,6 \cdot 3,6+25,3 \cdot 1,08+23 \cdot 0,42+20,7 \cdot 0,21+14,8 \cdot 0,105+0,035 \cdot 12,6}{100}=0,491 \mathrm{мм} .
$$

Гистограмма распределения твердых частиц хвостов приведена на рис.2. 
Гидротранспорт сгущенных хвостов обогащения железной руды...

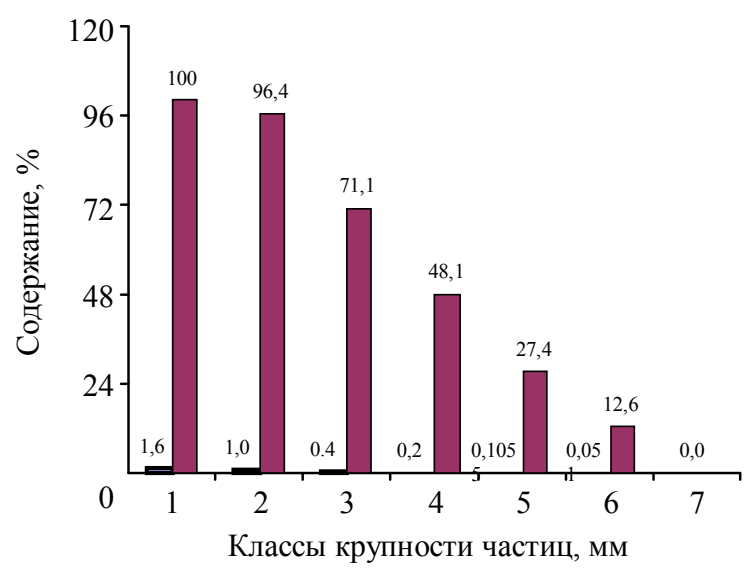

Рис.2. Гистограмма распределения твердых частиц по классам крупности

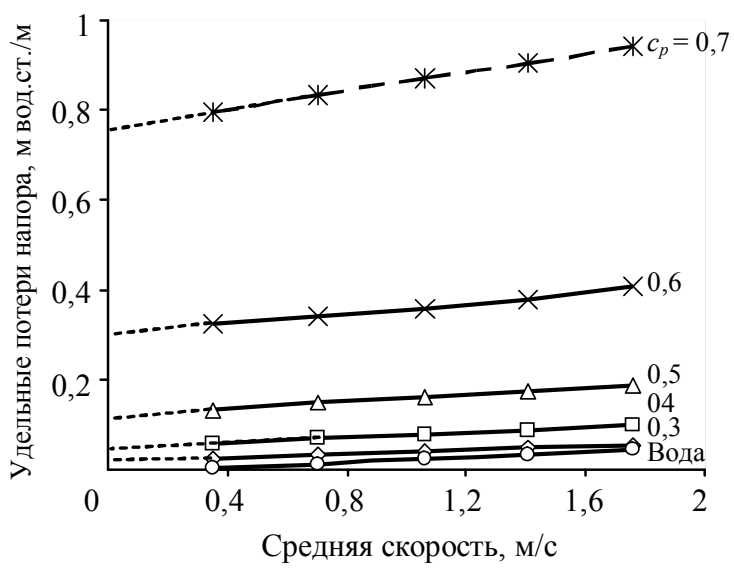

Рис.3. График зависимости потерь напора от средней скорости потока гидросмеси, $D_{\text {тр }}=0,05 \mathrm{M}$

Анализ гранулометрического состава производился путем отбора проб, фильтрации, сушки и просеивания сухого материала через стандартный набор сит. Определение количества материала производилось взвешиванием отдельных фракций. Точность ситового анализа на механическом анализаторе составляла $5 \%$ [7].

Замеренные средние значения потерь напора, полученные при экспериментальных исследованиях течения по трубопроводу гидросмесей хвостов обогащения железной руды четырех концентраций, приведены в табл.1. Графические зависимости потерь напора от средней скорости потока смеси по данным лабораторных экспериментов приведены на рис.3.

Таблииа 1

Экспериментальные данные течения гидросмесей хвостов обогащении железной руды в трубопроводе $\left(D_{\text {тр }}=0,05\right.$ м)

\begin{tabular}{c|c|c|c|c|c|c|c}
\hline \multirow{2}{*}{$\begin{array}{c}\text { Средняя ско- } \\
\text { рость, м/с }\end{array}$} & 30 & 40 & 50 & 60 & 70 (теория) & \begin{tabular}{c} 
Вода \\
\cline { 2 - 7 }
\end{tabular} & $\begin{array}{c}\text { Число Re } \\
\text { (вода) }\end{array}$ \\
\hline 0,352 & $0,026 / 1075^{*}$ & $0,057 / 790$ & $0,134 / 590$ & $0,323 / 440$ & $0,797 / 343$ & 0,003 & 17300 \\
0,704 & $0,033 / 2150$ & $0,069 / 1590$ & $0,148 / 1190$ & $0,342 / 890$ & $0,833 / 686$ & 0,012 & 34600 \\
1,06 & $0,041 / 3200$ & $0,078 / 2390$ & $0,162 / 1780$ & $0,360 / 1340$ & $0,87 / 1033$ & 0,024 & 52100 \\
1,41 & $0,048 / 4300$ & $0,088 / 3180$ & $0,175 / 2360$ & $0,380 / 1780$ & $0,906 / 1374$ & 0,039 & 69320 \\
1,76 & $0,056 / 5370$ & $0,098 / 3970$ & $0,189 / 2950$ & $0,41 / 2230$ & $0,94 / 1715$ & 0,058 & 86530
\end{tabular}

${ }^{*}$ В числителе - потери напора, м, в знаменателе критерий Re.

Из рис. 3 и табл. 1 следует, что на всех исследованных концентрациях гидросмеси проявляют свойства неньютоновских жидкостей. В нижней части кривых при скоростях течения около $1 \mathrm{~m} / \mathrm{c}$ и до 0,5 м/с (для всех гидросмесей) имеется линейный участок, свидетельствующий о ламинарном режиме течения.

Потери напора увеличиваются при повышении концентрации твердого материала, что хорошо видно на рис.3. Наклон линейных участков возрастает при росте объемной концентрации. Пунктирными линиями, проведенными в продолжение линейных участков кривых от точки с минимальной средней скоростью потока смеси, на оси потерь напора отсекаются ординаты, соответствующие начальному уклону $i_{0}$. Значения начального уклона увеличиваются при росте концентрации (рис.4).

Начальный гидравлический уклон свидетельствует о неньютоновском характере потока смеси. Для концентрированных гидросмесей хвостов

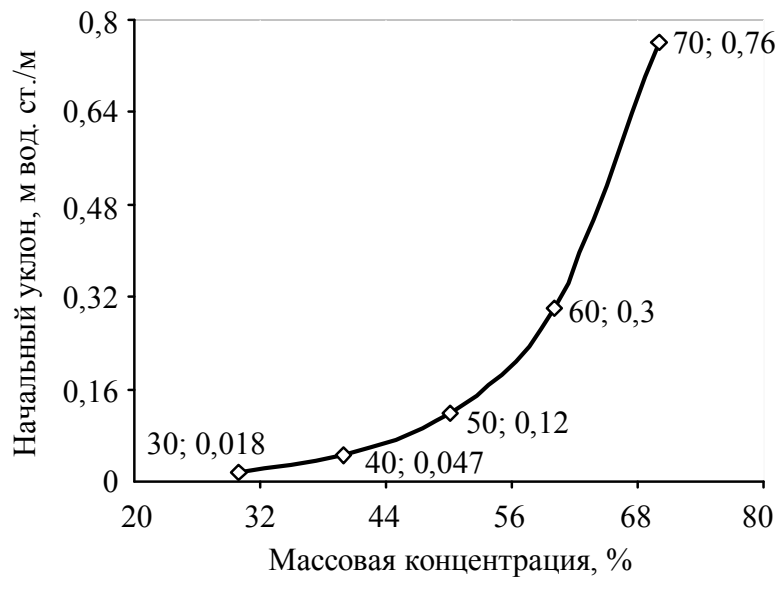

Рис.4. Изменение начального уклона от концентрации твердой фазы гидросмеси 
обогащения железной руды, твердая фаза которых содержит в основном частицы относительно мелких классов $\left(d_{\mathrm{o}}=0,491\right.$ мм с преобладающим классом $-0,044$ до $\left.80 \%\right)$, характерно образование внутренней структуры за счет сил сцепления и коагуляции отдельных частиц, распределенных в жидкой непрерывной среде.

Начальные потери напора - результат суммы сопротивлений от сил сцепления между частицами и сил трения между ними, т.е.:

$$
i_{0}=i_{p}+i_{f},
$$

где $i_{0}$ - начальный уклон; $i_{p}$ - часть начального уклона, обусловленная силами сцепления между частицами; $i_{f}$ - часть начального уклона от сил трения между частицами.

Кривая на рис. 4 описывается формулой

$$
i_{0}=\frac{0,496 \cdot 10^{4,525 \cdot c_{p}}}{\rho_{\text {см }} g D} .
$$

Начальный уклон, как следует из приведенной формулы, зависит от концентрации твердых частиц хвостов обогащения и диаметра трубопровода. В табл.2 приведены расчетные значения начального уклона для различных концентраций и диаметров трубопровода.

Таблица 2

\begin{tabular}{c|c|c|c|c|c|c}
\hline \multicolumn{7}{|c}{ Начальный уклон, м вод. ст./м для диаметра трубы, м } \\
\cline { 2 - 7 } Массовая концентрация $c_{p}$ & 0,05 & 0,1 & 0,2 & 0,4 & 0,5 & 1,0 \\
\hline 0,3 & 0,0182 & 0,009 & 0,004 & 0,002 & 0,0018 & 0,001 \\
0,4 & 0,048 & 0,024 & 0,012 & 0,006 & 0,005 & 0,002 \\
0,5 & 0,121 & 0,06 & 0,03 & 0,015 & 0,012 & 0,006 \\
0,6 & 0,305 & 0,153 & 0,076 & 0,038 & 0,03 & 0,015 \\
0,7 & 0,761 & 0,381 & 0,19 & 0,095 & 0,076 & 0,038
\end{tabular}

Из табл.2 видно, что с увеличением концентрации твердых частиц начальный уклон возрастает, а с увеличением диаметра трубопровода - уменьшается. При запуске насосной установки системы гидротранспорта необходимо, чтобы развиваемый напор был больше начального уклона.

Анализ экспериментальных зависимостей удельных потерь напора от средней скорости потока гидросмеси показывает, что гидросмеси в диапазоне массовых концентраций от 30 до 60 \% представляют собой неньютоновские жидкости, течение которых описывается уравнением Бингама - Шведова $[11,12]$. Из-за высоких значений концентрации режим течения в трубопроводе $D=50$ мм практически на всех концентрациях ламинарный и переходной к турбулентному режиму. Общее уравнение для потерь напора можно записать в следующем виде:

$$
i_{\mathrm{M} / \mathrm{M}}=\frac{4\left(\tau_{0}+\eta_{\ni ф} \frac{8 v}{D}\right)}{\rho_{\text {см }} g D},
$$

где $\tau_{0}$ - начальное напряжение сдвига, Па; $\eta_{э ф}-$ динамический коэффициент эффективной вязкости, Па·с; $v$ - средняя скорость потока гидросмеси, м/с; $D$ - диаметр трубопровода, м; $\rho_{\mathrm{cm}}-$ плотность гидросмеси, кг $/ \mathrm{M}^{3} ; g-$ ускорение силы тяжести, м/ $\mathrm{c}^{2}$.

Результаты лабораторных исследований позволяют предварительно оценить величину потерь напора в трубопроводах другого диаметра, например в промышленном трубопроводе диаметром $D N 1000$, используя метод теории подобия гидродинамических процессов [5].

В соответствии со второй теоремой подобия для подобных процессов дифференциальные уравнения движения можно заменить уравнением из чисел подобия:

$$
f\left(K_{1}, K_{2}, K_{3}, \ldots\right)=0 .
$$

где $K_{i}$ - числа подобия. 
Гидротранспорт сгущенных хвостов обогащения железной руды...

Для случая подобия гидродинамических потоков жидкости эта функция имеет вид

$$
f(\mathrm{Eu}, \mathrm{Re}, \mathrm{Fr})=0,
$$

где $\mathrm{Eu}$ - число Эйлера (отношение сил давления к силам инерции); Re - число Рейнольдса (отношение сил инерции к силам вязкости); $\mathrm{Fr}$ - число Фруда (отношение сил инерции к силам тяжести).

Последнее уравнение можно записать в следующем виде

$$
A\left(\operatorname{Eu}^{n} \operatorname{Re}^{m} \operatorname{Fr}^{q}\right)=0 .
$$

В данном уравнении имеются определяемые и определяющие числа подобия. Определяемым числом подобия является число Эйлера, так как оно содержит искомую величину потерь давления. В связи с этим можно переписать последнее равенство:

$$
\mathrm{Eu}=A\left(\operatorname{Re}^{m} \operatorname{Fr}^{q} i_{L}\right),
$$

где $i_{L}=L / D-$ инвариант геометрического подобия.

B этих уравнениях число Fr при течении в горизонтальных трубах не имеет существенного значения и им можно пренебречь. Тогда в окончательном виде уравнение подобия при течении жидкостей в горизонтальных трубах будет иметь вид:

$$
\mathrm{Eu}=A\left(\operatorname{Re}^{m} i_{L}\right) .
$$

В гидродинамике известно уравнение подобия для горизонтального течения вязкой ньютоновской жидкости

$$
\mathrm{Eu}=k \operatorname{Re}^{-0,25}\left(\frac{L}{D}\right)
$$

где коэффициент $k=0,158[5]$.

Для неньютоновской жидкости, к которой относятся сгущенные гидросмеси хвостов обогащения, необходимо определить значение этого коэффициента.

Преобразуем полученное уравнение подобия, записав значение определяемого числа Эйлера

$$
\frac{\Delta P}{\rho_{\mathrm{cm}} v^{2}}=k \operatorname{Re}^{-0.25}\left(\frac{L}{D}\right) \rightarrow \frac{\rho_{\mathrm{cm}} g h}{\rho_{\mathrm{cm}} v^{2} L}=k \frac{\operatorname{Re}^{-0,25}}{D} \rightarrow \frac{h}{L}=k \frac{\rho_{\mathrm{cm}} v^{2} \operatorname{Re}^{-0,25}}{\rho_{\mathrm{cm}} g D} .
$$

В итоге имеем равенство

$$
i=k \operatorname{Re}^{-0,25} \frac{v^{2}}{g D}=2 k \operatorname{Re}^{-0,25} \frac{v^{2}}{2 g D} .
$$

Для гидросмесей неньютоновских, проявляющих реологические свойства, и описываемых уравнением Бингама - Шведова, потери напора пропорциональны коэффициенту $\frac{\lambda}{(1-\sigma) k_{\mathrm{c \tau}}}$. Следовательно, можно приравнять

$$
2 k \operatorname{Re}^{-0,25}=\frac{\lambda}{(1-\sigma) k_{\mathrm{cT}}},
$$

откуда получим

$$
k=\frac{\lambda}{2(1-\sigma) k_{\mathrm{cr}} \operatorname{Re}^{-0,25}},
$$

где $\sigma=\tau / \tau_{0}-$ относительное напряжение сдвига; $k_{\text {ст }}-$ коэффициент структуры.

Из формулы видно, что величина коэффициента $k$ зависит от концентрации твердой фазы, так как относительное напряжение сдвига и коэффициент структуры являются функциями этой характеристики гидросмеси. 
Определим значение $k$ с учетом известных реологических характеристик гидросмесей $[6,10]$ :

$$
\begin{gathered}
c_{p}=30 \% ; \sigma=\frac{\tau_{0}}{\tau_{0}+\eta_{\ni \phi} \dot{\gamma}} ; \quad \tau_{0}=0,124 \cdot 10^{4,525 \cdot c_{3}}=0,124 \cdot 10^{4,525 \cdot 0,3}=2,82 \text { Па; } \\
\eta_{\text {эф }}=6,31 \cdot 10^{1,72 \cdot c_{p}}=20,7 \cdot 10^{-3} \Pi \mathrm{a} \cdot \mathrm{c} ; \quad \dot{\gamma}=\frac{8 v}{D}=\frac{8 \cdot 1,41}{0,05}=225,6 \mathrm{c}^{-1} ; \\
\sigma=\frac{2,82}{2,82+0,0207 \cdot 225,6}=0,376 ; \quad k_{\mathrm{cT}}=1+3,45 c_{\mathrm{oб}}=1+3,45 \cdot 0,115=1,4 .
\end{gathered}
$$

Возьмем значение скорости $v=1,41$ м/с (см. табл.1). Число Рейнольдса:

$$
\operatorname{Re}=\frac{v D \rho_{\mathrm{cm}}}{\eta_{\text {эф }}}=\frac{1,41 \cdot 0,05 \cdot 1264}{0,0207}=4305
$$

Примем по формуле Блазиуса

$$
\lambda=\frac{0,3164}{\operatorname{Re}^{0,25}}=0,04, \quad k=\frac{0,04}{2 \cdot(1-0,376) \cdot 1,4 \cdot 4305^{-0,25}}=0,1855 .
$$

Потери напора по формуле

$$
i=0,1855 \cdot 4305^{-0,25} \frac{1,41^{2}}{2 \cdot 9,81 \cdot 0,05}=0,05 \text { м вод. ст./м. }
$$

Из табл.1 находим, что фактические (замеренные) потери напора составляют 0,046 м вод. ст./м. Ошибка расчетных и опытных данных составляет

$$
\varepsilon=\frac{i_{\text {расч }}-i_{\text {факт }}}{i_{\text {факт }}}=\frac{0,05-0,046}{0,046} \cdot 100 \%=4,8 \% .
$$

Следовательно, разработанную методику пересчета потерь напора с одного диаметра трубопровода на другой можно использовать для предварительной оценки потерь напора.

Результаты. Опытно-промышленная установка для проведения испытаний гидротранспорта была смонтирована работниками ПНС-І ЦХХ (рис.5) [2, 9].

Гидросмесь с заданной концентрацией твердых хвостов обогащения перекачивалась грунтовым насосом $8 Г$ р-8 производительностью $Q=400 \mathrm{~m}^{3} /$ ч. Транспортная линия выполнена в виде петли, состоящей из двух трубопроводов - стального $D N 200$ и $D N 190$ с внутренним полиуретановым покрытием, Участок трубопроводной петли $D N 190$ расположен на 3 м ниже стального трубопровода.

На каждом трубопроводе имеется измерительный участок длиной $L=15$ м. На измерительных участках установлены пружинные манометры с разделителями сред для измерения перепада давления.

Расходный бак объемом $W=1,7$ м $^{3}$ был выполнен из трубы диаметром 1000 мм, высотой 2,5 м. Днище бака скошено в сторону всасывающего трубопровода. Поток гидросмеси всасывал-
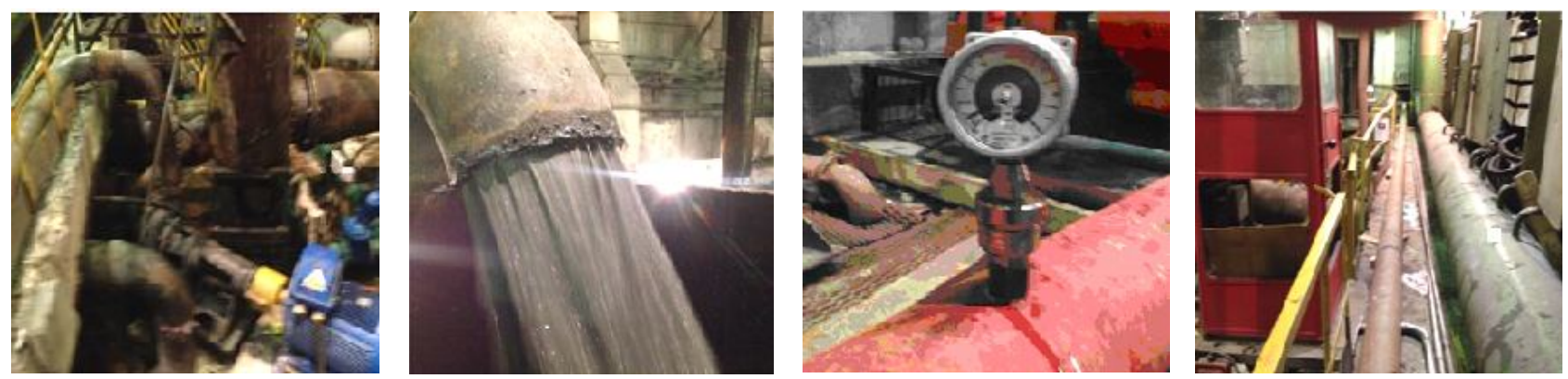

Рис.5. Отдельные элементы опытно-промышленной установки гидротранспорта хвостовой пульпы 
ся грунтовым насосом, транспортировался по трубопроводной петле и сливался в расходный бак. В расходный бак с помощью мостового крана засыпалась фиксированная масса твердых хвостов обогащения. Уровень гидросмеси в расходном баке и ее объем оставались постоянными. Массовая концентрация гидросмеси рассчитывалась по формуле

$$
c_{p}=\frac{M_{\mathrm{TB}}}{M_{\text {см }}}=\frac{M_{\mathrm{TB}}}{M_{\mathrm{B}}+M_{\mathrm{TB}}},
$$

где $c_{\mathrm{p}}$ - массовая концентрация гидросмеси, доли ед.; $M_{\text {тв }}$ - масса загружаемых в расходный бак твердых хвостов, кг; $M_{\text {в }}$ масса воды, численно равная объему воды, кг.

Перед началом основных экспериментов были проведены испытания на чистой воде. При этом проверялась работоспособность оборудования, насоса, приборов (ультразвуковой расходомер, манометры), герметичность соединений. Установка работала на ожидаемых номинальных характеристиках. Расходомер и манометры показывали стабильные расчетные значения. Объем жидкости в расходном баке оставался постоянным на уровне сливного отверстия.

Измеренные параметры гидротранспорта хвостов обогащения, полученные при проведении опытно-промышленных испытаний, приведены в табл.3 и на рис.6.

Таблица 3

Значения потерь напора по экспериментальным данным

\begin{tabular}{c|c|c|c|c|c|c|c}
\hline \multirow{2}{*}{$\begin{array}{c}\text { Концентрация, } \\
\text { доли ед. }\end{array}$} & $\begin{array}{c}\text { Плотность, } \\
\text { кг/м }{ }^{3}\end{array}$ & \multicolumn{2}{|c|}{ Скорость в трубопроводах, м/с } & \multicolumn{2}{|c|}{$\begin{array}{c}\text { Потери напора в трубопроводах, } \\
\text { м вод. ст.м }\end{array}$} & \multicolumn{2}{|c}{ Коэффициент сопротивлений $\lambda$} \\
\cline { 2 - 7 } & Стальной & Футерованный & Стальной & Футерованный & Стальной & Футерованный \\
\hline 7 & 1051 & 3,82 & 4,23 & 0,062 & 0,04 & 0,016 & 0,008 \\
13 & 1100 & 3,88 & 4,3 & 0,088 & 0,06 & 0,021 & 0,011 \\
19 & 1152 & 3,85 & 4,27 & 0,113 & 0,078 & 0,026 & 0,014 \\
24 & 1200 & 3,73 & 4,14 & 0,127 & 0,099 & 0,030 & 0,018 \\
29 & 1253 & 3,66 & 4,06 & 0,149 & 0,105 & 0,035 & 0,019 \\
34 & 1310 & 3,54 & 3,92 & 0,163 & 0,124 & 0,039 & 0,023 \\
38 & 1361 & 3,49 & 3,86 & 0,182 & 0,12 & 0,043 & 0,022 \\
42 & 1414 & 3,41 & 3,78 & 0,192 & 0,125 & 0,046 & 0,023 \\
45 & 1458 & 3,29 & 3,64 & 0,197 & 0,151 & 0,049 & 0,029 \\
49 & 1517 & 3,15 & 3,49 & 0,199 & 0,148 & 0,052 & 0,03 \\
52 & 1568 & 2,98 & 3,3 & 0,195 & 0,142 & 0,055 & 0,031 \\
53 & 1584 & 2,91 & 3,22 & 0,191 & 0,136 & 0,056 & 0,031
\end{tabular}

Результаты экспериментов показывают, что удельные потери напора в экспериментальном футерованном трубопроводе $D N 190$ в 1,4 раза меньше, чем в стальном трубопроводе $D N 200$. Необходимо учесть, что футерованный трубопровод был меньшего диаметра, что привело к большей скорости потока гидросмеси, от которой зависит кинетическая энергия потока и, следовательно, потери на трение. При равных диаметрах трубопроводов соотношение потерь напора в стальном и футерованном трубопроводах составило бы не менее 1,75 .

Покажем это на конкретном пересчете (табл.3).

Расчет производим по формуле

$$
i=\lambda \frac{v^{2}}{2 g D} \frac{\rho_{c}}{\rho_{0}} .
$$

Принимаем среднюю скорость в футерованном трубопроводе, равной скорости в стальном трубопроводе,

$$
v_{\text {с т }}=v_{\text {фут }} .
$$

Зададимся концентрацией пульпы $c_{p}=49 \%$.

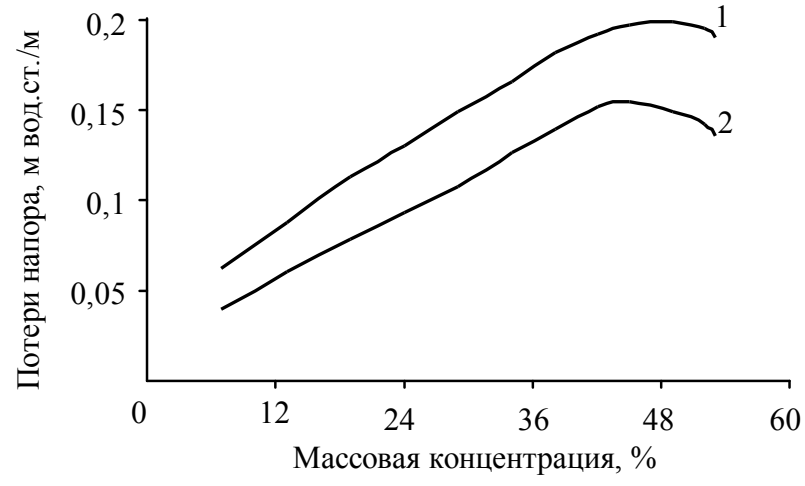

Рис.6. Потери напора в трубопроводах при изменении концентрации гидросмесей

1 - стальной трубопровод, $D=200$ мм; 2 - футерованный, $D=190$ мм 


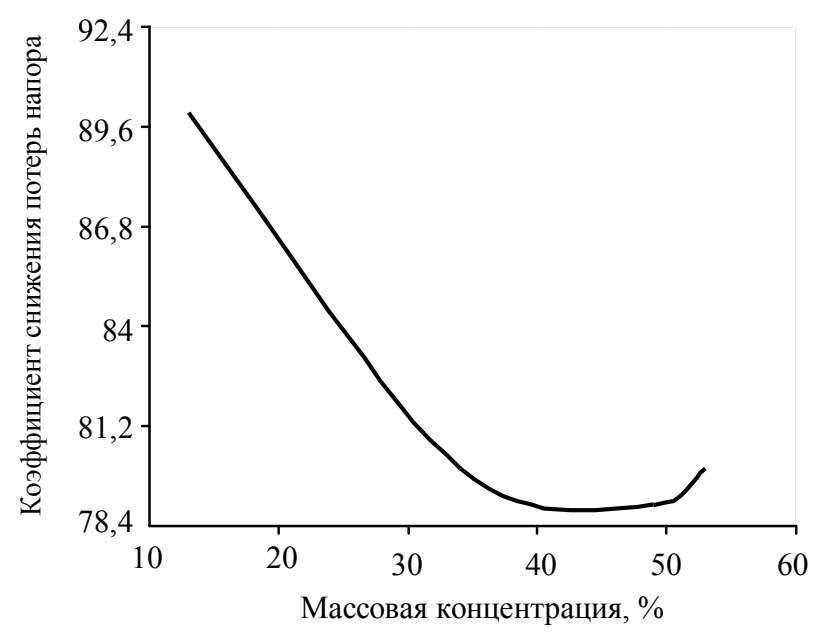

Рис.7. Коэффициент снижения потерь напора от концентрации пульпы в футерованном трубопроводе $D N 200$ по отношению к стальному трубопроводу $D N 200$

Рассчитаем коэффициент гидравлических сопротивлений по формуле, полученной для футерованного трубопровода,

$$
\lambda=0,05 c_{p}+0,0045=0,05 \cdot 0,49+0,0045=0,029 .
$$

Данная формула получена при обработке опытных данных [3].

Для концентрации 49 \% плотность пульпы равна 1517 кг/м ${ }^{3}$, скорость пульпы равна $3,15 \mathrm{~m} / \mathrm{c}$.

Потери напора в футерованном трубопроводе диаметром 200 мм

$$
i=0,029 \frac{3,15^{2}}{2 \cdot 9,81 \cdot 0,2} 1,517=0,111 \mathrm{~m} / \mathrm{M}
$$

Относительное уменьшение потерь напора в футерованном трубопроводе

$$
\varepsilon=\frac{i_{\text {ст }}}{i_{\text {фут }}}=\frac{0,199}{0,111}=1,79 ; \quad \varepsilon_{1}=\frac{i_{\text {ст }}-i_{\text {фут }}}{i_{\text {фут }}} \cdot 100 \%=\frac{0,199-0,111}{0,111} \cdot 100 \%=79 \% .
$$

Был выполнен пересчет значений потерь напора для футерованного трубопровода при работе на других концентрациях (табл.3, рис.7). График на рис.7 показывает, что во всем диапазоне концентраций гидросмеси хвостов обогащения железной руды потери напора в футерованном полиуретановым покрытием трубопроводе $D N 200$ не менее, чем в 1,75 раз меньше, чем в стальном трубопроводе $D N 200$ без покрытия.

Результаты выполненных лабораторных и опытно-промышленных исследований приняты для использования в проекте реконструкции системы гидротранспорта сгущенных хвостов обогащения Качканарского ГОКа в соответствии с планом развития хвостового хозяйства ЦХХ ЕВРАЗ «Качканарский ГОК».

\section{Выводы}

1. При существующем на данный момент выходе хвостов с обогатительной фабрики «ЕВРАЗ КГОК» в размере 4903 т/ч, в том числе секции 1-15 в объеме 2509 т/ч, секции 16-29 в объеме 2394 т/ч, и принимаемой степени сгущения исходной хвостовой пульпы на проектируемых комплексах сгущения КС-1 и КС-2 до 40 \% по весу, для оптимизации системы гидротранспорта сгущенных хвостов на участке от ПНС II до комплекса гидроциклонирования необходимо предусматривать применение труб с внутренним полиуретановым покрытием.

2. Применение пульповодов с внутренним полиуретановым покрытием позволяет осуществить подачу сгущенной пульпы для складирования на дальних отсеках хвостохранилища.

3. Выполненный анализ применения пульповодов с полиуретановым покрытием на технологическом участке подачи сгущенных хвостов в сравнении со стальными трубами показывает, что экономический эффект достигается уже в первые 3-4 года эксплуатации пульповода, и за 4-5 лет эксплуатации обеспечит полную окупаемость первоначальных капитальных затрат.

4. Применение стальных труб с внутренним полиуретановым покрытием позволяет сократить затраты электроэнергии на гидротранспорт сгущенных хвостов в сравнении со стальной трубой в среднем на $22-24 \%$.

5. Затраты жизненного цикла за 10 лет эксплуатации труб с полиуретановым покрытием на технологическом участке гидротранспорта сгущенных хвостов в два раза дешевле эксплуатации стальных труб без покрытия. 
Гидротранспорт сгущенных хвостов обогащения железной руды...

\section{ЛИТЕРАТУРА}

1. Александров В.И. Энергетическая эффективность гидравлического транспорта хвостов обогащения железной руды на Качканарском ГОКе / В.И.Александров, С.А.Тимухин, П.Н.Махараткин // Записки Горного института. 2017. Т. 225. C. 330-337. DOI: 10.18454/PMI.2017.3.330

2. Александров В.И. Энергетическая эффективность применения труб, футерованных полиуретаном / В.И.Александров, И.А.Дедушенко, С.Ю.Авксентьев // Обогащение руд. 2017. № 2. С. 54-59.

3. Александрова T.H. Экологические и технологические аспекты утилизации зольных и шлаковых отходов / Т.Н.Александрова, С.А.Корчевенков // Журнал экологической инженерии. 2017. № 4. Т. 18. С 15-24.

4. Борисенко Л.Ф. Лабораторные и технологические исследования минерального сырья / Л.Ф.Борисенко, Л.М.Делицын и др.; ЗАО «Геоинформмарк». М., 1997. 65 с.

5. Васильева М.А. Исследование полимерного материала рабочей камеры-канала магнитного насоса для перекачивания тяжелых нефтей / М.А.Васильева, С.Фёйт // Записки Горного института. 2016. Т. 221. С. 651-654. DOI: 10.18454/PMI.2016.5.651

6. Гусев В.П. Основы гидравлики / Изд-во ТПУ. Томск, 2009. 172 с.

7. Ромашев А.О. К вопросу статистической проверки данных для обогащения руд различного генезиса / А.О.Ромашев, T.Н.Александрова // ARPN Journal of Engineering and Applied Sciences. 2017. № 19. T. 12. С. 5613-5619.

8. Alexandrov $V$. Estimation of efficiency of hydrotransport pipelines polyurethane coating compared to steel pipelines / V.Alexandrov, M.Vasilyeva // International Conference on Transport and Sedimentation of Solid Particles. Praque, 2017. P. 19-26.

9. Aleksandrov V.I. Estimation of efficiency of hydrotransport pipelines polyurethane coating application in comparison with steel pipelines / V.I.Aleksandrov, M.A.Vasilyeva, I.B.Pomeranets // Earth and Environmental Science. 2017. № 87(2). P. 22001.

10. Berta M. Correlation between in-line measurements of tomato ketchup shear viscosity and extensional viscosity/M.Berta, J.Wiclund, R.Kotse // Journal of Food Engineering. 2016. Vol. 173. P. 8-14.

11. Heywood N. Developments in slurry pipeline technologies / N.Heywood, J.Alderman // Chemical Engineering Progress. 2003. Iss. 4. P. 100-107.

12. Slurry Transport Using Centrifugal Pumps / K.C.Wilson, G.R.Addie, S.Aellgren, R.Clift. US: Springer, 2006.

13. Vlasak P. Fully stratified particle-laden flow in horizontal circular pipe / P.Vlasak, B.Kysela, Z.Chara // Particulate Science and Technology. 2014. Vol. 32. № 2. P. 179-182.

Авторы: В.И.Александров, д-р техн. наук, профессор, Aleksandrov_VI@pers.spmi.ru (Санкт-Петербургский горный университет, Санкт-Петербург, Россия), М.А.Васильева, канд. техн. наук, доиент, vasileva_ma@pers.spmi.ru (CaнкmПетербургский горный университет, Санкт-Петербург, Россия).

Статья поступила в редакиию 11.03.2018.

Статья принята к публикачии 25.05.2018. 